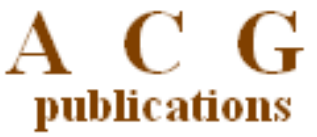

J. Chem. Metrol. 11:1 (2017) 9-15

journal of chemical metrology

\title{
Accurate determination of ethanol in water by qNMR: Validation and uncertainty assessment
}

\author{
İlker Ün* and Ahmet C Goren
}

\author{
TUBITAK, UME, P.Box:54 41470 Gebze-Kocaeli, Türkiye
}

(Received February 27, 2017; Revised March 23, 2017; Accepted March 25, 2017)

\begin{abstract}
A rapid and simple method, having high reproducibility and low uncertainty for determination of low concentration of ethanol in water has been developed by using qNMR. Method validation was performed applying CRM and calibration solutions. The correlation coefficient for the analyte in the calibration interval was 1 . At a concentration range of $0.5 \mathrm{mg} / \mathrm{g}$ to $5 \mathrm{mg} / \mathrm{g}$, the recovery was determined to be $99.71 \%$. The relative uncertainties for ethanol solutions of $0.8123 \mathrm{mg} / \mathrm{g}$ and $3.8029 \mathrm{mg} / \mathrm{g}$ in water were found to be $0.0053 \mathrm{mg} / \mathrm{g}$ and $0.0027 \mathrm{mg} / \mathrm{g}$, respectively.
\end{abstract}

Keywords: qNMR; ethanol; traceability; method validation; uncertainty. (C) 2017 ACG Publications. All rights reserved.

\section{Introduction}

qNMR applications is now widely available in various fields, such as drug industry [1], manufacturing of reference materials [2], food analyses [3,4] and metabolite determination in human body fluids [5-11]. Moreover, applications of qNMR involve determination of purity of a compound and amount and concentration of a sample inside a matrix. NMR is the sole method, which can determine, with one analysis, a small molecule having a single proton or an oligosaccharide possessing multiple protons. In addition to its easy and quick sample preparation procedure, recovering the sample after the analysis is possible especially in case of using external standard method, which is not possible with chromatographic techniques. While the reference material is used as independent of the sample in qNMR, it must have a structural similarity to the sample in chromatographic analyses Also, the chromatographic techniques require calibration curve, but it is up to the operator in qNMR. Due to its practical and reliable results, it looks, qNMR will attract even more interest in near future with upcoming cost reductions.

Following quantitative determinations of active substances in drug and food supplements by qNMR [12], a rapid measure of alcohol concentration in food samples, with high accuracy and lower uncertainty is possible. qNMR can be used as an alternative and practical method for determination the amount of ethanol instead of GC-MS in food samples [13]. This method is particularly applicable for liquid samples such as wine [14] and alcohols in frozen fruit extracts [15]. In European pharmacopeia, the limits for the presence of organic solvents in drug samples have already been established. Ethanol has a concentration limit of $5000 \mathrm{ppm}$ per day as it displays a lower toxicity [16].

The aim of this study is to determine the amount of ethanol in water samples at high and low concentration levels. The developed method will be fully validated and measurement uncertainty will be evaluated.

\footnotetext{
* Corresponding author: E-Mail: ilker.un@tubitak.gov.tr, Tel.:(+90) 2626795000 - 6109

The article was published by Academy of Chemistry of Globe Publications www.acgpubs.org/jcm (c) Published 03/31/2017 EISSN:1307-6183

http://doi.org/10.25135/jcm.2.17.03.035
} 


\section{Experimental}

\subsection{Chemicals}

Sample for applications; Ethanol-Water Solution $(0.5 \%$ and $0.05 \%)$. Sample for trueness studies; Standard Reference Material 2894 NIST. Internal standard for ethanol concentration; 3(Trimethylsilyl)propionic-2,2,3,3- $\mathrm{d}_{4}$ acid sodium salt (TSP- $\left.\mathrm{d}_{4}\right)$ Sigma Aldrich. NMR Solvent; Deuterium oxide $99.9 \%$ Merck. Internal standard for TSP- $\mathrm{d}_{4}$ purity; Benzoic acid Standard Reference Material NIST 350b. Certified reference material for traceability; Chloramphenicol Primary Calibrant UME CRM 1301 (certified value 99.58\% $\pm 0.15 \%$ ).

\section{2. qNMR Conditions}

All NMR experiments were performed at $298.15 \mathrm{~K}$ on a Varian VNMRS 600 spectrometer (Varian, San Francisco, CA, USA) operating at $599.747 \mathrm{MHz}$ for proton $\left({ }^{1} \mathrm{H}\right)$ resonance frequency equipped with a $5 \mathrm{~mm}$ One NMR probe using $5 \mathrm{~mm}$ sample tubes $(5 \mathrm{~mm}$ diameter, $178 \mathrm{~mm}$ length, Duran Group, Mainz, Germany). The VnmrJ 4.2 (Agilent Technologies, Santa Clara, CA, USA) and MestReNova 11.0.0 (Mestrelab Research S.L., Santiago de Compostela, Spain) softwares were used for data acquisition and data processing, respectively. More detailed phase and baseline correction can be done with MestReNova software. For this reason, MestReNova software was used for data processing.

${ }^{1} \mathrm{H}$ NMR experiments were recorded with 32 scans without sample spinning. The measurements were conducted with the following parameters optimized for ${ }^{1} \mathrm{H}$ NMR: pulse angles of $90^{\circ}, 64 \mathrm{k}$ data points, acquisition time of $4 \mathrm{~s}$ and auto gain function. $T_{1}$ was approximately $3.48 \mathrm{~s}$ for ethanol $-\mathrm{CH}_{3}$ resonance, and $6.50 \mathrm{~s}$ for TSP- $\mathrm{d}_{4}-\mathrm{CH}_{3}$ resonance. $15 \mathrm{xT} 1$ was used to ensure a complete relaxation and reducing the influence of relaxation delay. Therefore the relaxation delay between two scans was set to $98 \mathrm{~s}$. Spectral width of $9615.4 \mathrm{~Hz}$ and transmitter offset at $0.59 \mathrm{ppm}$ were applied. Fourier transformation was performed after zero filling the data to $64 \mathrm{k}$ time domain points. Prior to Fourier transformation, an exponential line-broadening function of $0.2 \mathrm{~Hz}$ was applied to FID (Free Induction Decay) in all NMR experiments. During the data processing, phase and baseline were corrected manually and the signals were also integrated manually for the same region. Chemical shift was referenced to the TSP- $\mathrm{d}_{4}$ signal at $0.00 \mathrm{ppm}$ in $\mathrm{D}_{2} \mathrm{O}$. Each sample was measured once due to the long analysis period, and the concentrations were calculated with the mean of the parallel detection results.

\subsection{Sample preparation}

The weighing processes were performed on a micro balance (XP56, Mettler-Toledo GmbH, Switzerland) with a readability of $0.001 \mathrm{mg}$, certified by UME (TÜBİTAK National Metrology Institute) and checked with the class E2 weights. The balance is positioned on a $500 \mathrm{~kg}$ stone table, with a U-electrode in place to remove potential static charge. Screw cap clear glass vials with the capacity of $4 \mathrm{ml}$ were used for sample preparation. Firstly, an empty vial was weighed and then TSP$\mathrm{d}_{4}$ was added as an internal reference (3-8 $\mathrm{mg}$ ) into the vial. The weighing was repeated 3 times for the empty vial and internal standard. Finally, water sample which contains ethanol was weighed $(0.4 \mathrm{~mL})$ quickly in the same vial. $0.6 \mathrm{~mL} \mathrm{D}_{2} \mathrm{O}$ was added into the vial and screw cap was tightly closed. The solutions were mixed via vortex until a clear solution was obtained. Then, $0.7 \mathrm{~mL}$ of solution was transferred into a NMR tube.

\section{Results and discussion}

\subsection{Theory}

Quantitative determination of ethanol concentration by qNMR was conducted by dissolving the sample with known quantity together with the internal standard in completely deuterated water. 
The quantitative value was calculated using integral values of ethanol and the internal standard signals in the spectrum. In order to determine the correct integral values, phase and baseline corrections of the spectrum were made manually. The calculation equation of qNMR for the analyte purity is as follows:

$$
C_{E t O H}=\frac{I_{E t O H}}{I_{S t d}} \frac{N_{S t d}}{N_{E t O H}} \frac{M_{E t O H}}{M_{\text {Std }}} \frac{m_{\text {Std }}}{m_{\text {Sample }}} P_{\text {Std }}
$$

$I_{S t d}, N_{S t d}, M_{S t d}, m_{S t d}$ and $P_{S t d}$ are the peak area, number of proton, molecular weight, weighed mass and purity of the internal standard, respectively. The terms $I_{E t O H}, N_{E t O H}, M_{E t O H}$, and $C_{E t O H}$ indicate the peak area, number of proton, molecular weight and concentration of the analyte (ethanol), $m_{\text {Sample }}$ weighed mass for ethanol in water sample respectively.

\subsection{Method Validation}

Trueness, linearity, limit of detection (LOD), limit of quantification (LOQ), specificity and selectivitiy parameters were evaluated to validate the method. Additionally, traceability was established to obtain comparable results and measurement uncertainty was calculated.

\subsubsection{Trueness}

In order to assess trueness, two different ways were followed, in the first method the NIST 2894 standard reference material, in which ethanol concentration was reported as $1.0084 \mathrm{mg} / \mathrm{g} \pm$ 0.0083 , was used. The results of the analysis conducted with 5 different samples are given in Table 1 . When the obtained results were evaluated, it was determined that the ethanol concentration found by qNMR analysis and the certificate value of ethanol solution in water were very close to each other in terms of both concentration and uncertainty.

\begin{tabular}{lr} 
Table 1. qNMR results of NIST 2894 SRM \\
\hline NIST 2894 & $\begin{array}{r}\text { qNMR Results } \\
(\mathrm{mg} / \mathrm{g})\end{array}$ \\
\hline Sample 1 & 1.0063 \\
Sample 2 & 1.0203 \\
Sample 3 & 0.9996 \\
Sample 4 & 1.0167 \\
Sample 5 & 1.0032 \\
\hline Mean & 1.0092 \\
Standard Deviation & 0.0089 \\
\hline
\end{tabular}

In the second validation method, qNMR analyzes were performed by preparing ethanol water solution in 6 different concentrations between $0.5 \mathrm{mg} / \mathrm{g}$ and $5 \mathrm{mg} / \mathrm{g}$. Recovery studies were conducted through dilution of the standard stock solution to different concentrations. The average recovery value for linearity samples was found to be $99.71 \%$ and the relative standard deviation value was 1.52 (Table 2). Recovery was calculated according to the following formula.

$$
\text { Recovery }(100 \%)=\frac{\text { Measured Concentration }- \text { endegeneus concentration }}{\text { spiked concentration }} \times 100
$$


Table 2. Recovery evaluation by qNMR

\begin{tabular}{lccrr}
\hline Sample & $\begin{array}{c}\text { Spiked } \\
(\mathbf{m g} / \mathbf{g})\end{array}$ & $\begin{array}{c}\text { Found } \\
(\mathbf{m g} / \mathbf{g})\end{array}$ & $\begin{array}{c}\text { Expanded Uncertainty } \\
(\mathbf{m g} / \mathbf{g})\end{array}$ & Recovery \% \\
\hline Ethanol in Water 0,5 mg/g & 0.483 & 0.492 & 0.001 & 101.86 \\
Ethanol in Water 1 mg/g & 0.937 & 0.950 & 0.008 & 101.39 \\
Ethanol in Water 2 mg/g & 1.809 & 1.796 & 0.022 & 99.28 \\
Ethanol in Water 3 mg/g & 2.838 & 2.794 & 0.012 & 98.45 \\
Ethanol in Water 4 mg/g & 3.629 & 3.573 & 0.019 & 98.46 \\
Ethanol in Water 5 mg/g & 4.774 & 4.719 & 0.022 & 98.85 \\
\hline & & & Mean & 99.71 \\
& & & SD & 1.52 \\
& & & \% RSD & 1.52 \\
\hline
\end{tabular}

\subsubsection{Linearity}

The linearity was evaluated by preparing three different samples from each concentration and drawing a linearity pilot using the average values of these samples (Figure 1).

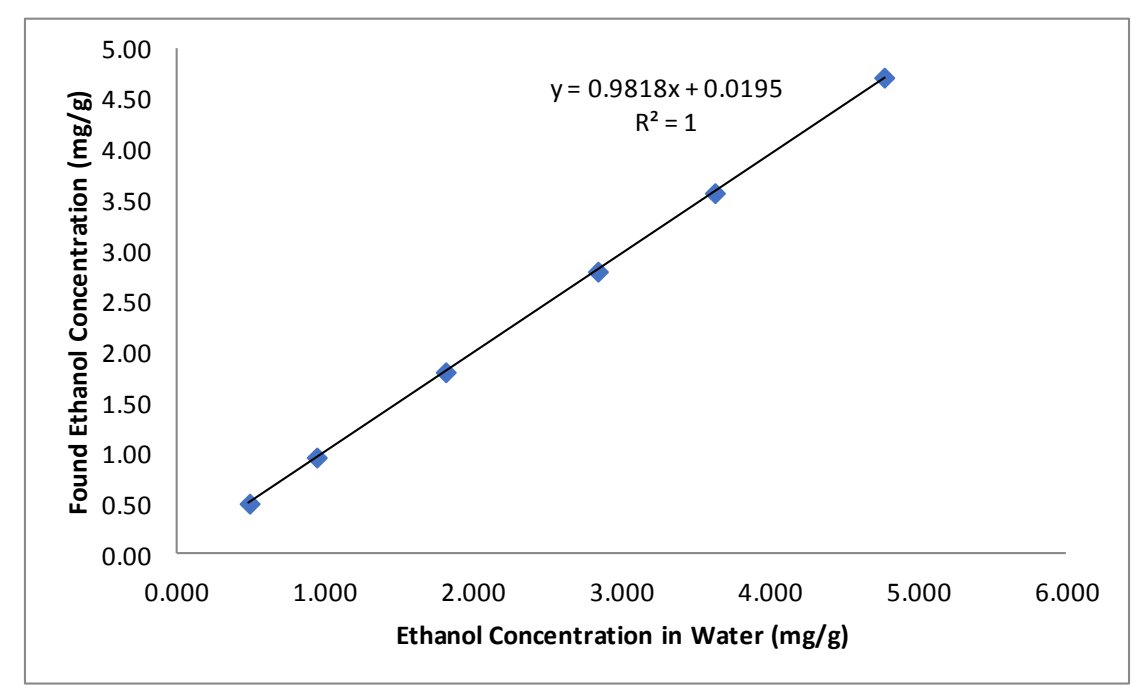

Figure 1. Linearity study pilot for ethanol concentration in water

\subsection{3. $L O D$ and $L O Q$}

LOD and LOQ values were studied with different samples by lowering ethanol concentration in water. The limit of detection (LOD) of the method was found to be $0.005 \mathrm{mg} / \mathrm{g}$ for ethanol. The limits of quantification (LOQ) was calculated to be $0.09 \mathrm{mg} / \mathrm{g}$, (for $\mathrm{S} / \mathrm{N}$ ratio $>100$ and the above concentrations).

\subsubsection{Specificity and selectivity}

Figure 3 shows ${ }^{1} \mathrm{H}$ NMR spectra of ethanol in water and TSP- $\mathrm{d}_{4}$ in $\mathrm{D}_{2} \mathrm{O}$. It was obvious that the signals obtained at $1.17(\mathrm{t}) \mathrm{ppm}$ for ethanol [17] and $0.02 \mathrm{ppm}$ for TSP- $\mathrm{d}_{4}$ were not disturbed by water and excipients. Moreover, the signals of ethanol and TSP- $\mathrm{d}_{4}$ were well separated from each other in sample preparations. A representative qNMR spectrum of ethanol in water sample is shown in Figure 2. 


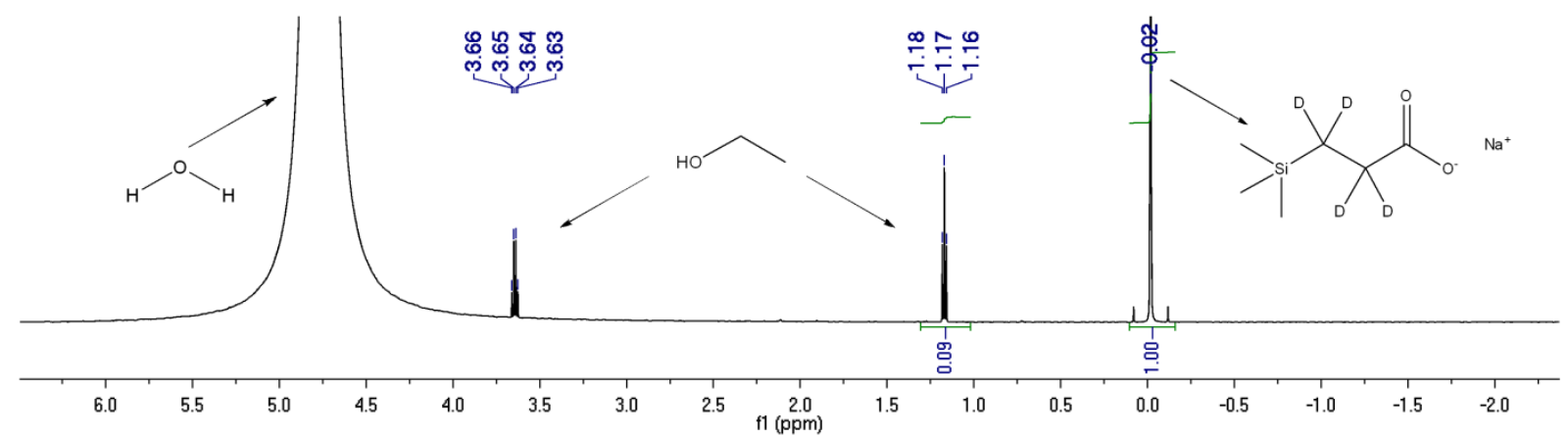

Figure 2. Representative qNMR spectrum of ethanol in water sample solved in $\mathrm{D}_{2} \mathrm{O}$

\subsection{Traceability}

In quantitative NMR analyzes, the TSP- $\mathrm{d}_{4}$ reference was used as the internal standard. TSP- $\mathrm{d}_{4}$ purity was determined by qNMR using the benzoic acid internal standard in the traceability chain of UME-CRM-1301 (chloramphenicol primary calibrator). Analyzes carried out on this basis were conducted by establishing a calibration chain that reaches the primary national or international standards, i.e. the International System of Units (SI).

\subsection{Estimation of Uncertainty}

The combined uncertainty $u(C x)$ containing additional quantities were calculated via equation (3), according to the literature [18] for determination of ethanol concentrations (Table 4). The letter X represents the ethanol.

$$
u\left(C_{X}\right)=C_{X} \sqrt{\left(\frac{u\left(I_{x} / I_{\text {std }}\right)}{I_{x} / I_{\text {std }}}\right)^{2}+\left(\frac{u\left(M_{x}\right)}{M_{x}}\right)^{2}+\left(\frac{u\left(M_{\text {std }}\right)}{M_{\text {std }}}\right)^{2}+\left(\frac{u\left(m_{\text {sample }}\right)}{m_{\text {sample }}}\right)^{2}+\left(\frac{u\left(m_{\text {std }}\right)}{m_{\text {std }}}\right)^{2}+\left(\frac{u\left(P_{\text {std }}\right)}{P_{\text {std }}}\right)^{2}}
$$

Equation (4) was used for the calculation of uncertainty component of molar masses $u(M)$. Where, $N_{j}$ indicates the number of atoms of the element $\mathrm{j}$ (e.g. C, H, etc.) and $u(j)$ indicates the uncertainties of the atom masses.

$$
u(M)=\sqrt{\sum_{j=1}^{n}\left(N_{j} u(j)\right)^{2}}
$$

The uncertainties of the initial weighing $\mathrm{u}(\mathrm{m})$, given by the uncertainty parameters of balance, were calculated using equation (5).

$$
u\left(m_{i}\right)=\sqrt{u_{w}^{2}(m)+2 u_{\text {non-linear }}^{2}(m)}
$$

Table 4. Results from uncertainty evaluation of the ${ }^{1} \mathrm{qNMR}$ method

\begin{tabular}{lrrr}
\hline & Value $(\mathrm{x})$ & $\mathrm{u}(\mathrm{x})$ & $\mathrm{u}(\mathrm{x}) / \mathrm{x}$ \\
\hline Ethanol Concentration (\%) & 0.081232 & 0.000192 & 0.002362 \\
Reference Purity (\%) & 96.120000 & 0.107500 & 0.001118 \\
$\mathrm{M}_{\mathrm{W}}$ Ethanol (g/mol) & 46.068440 & 0.000971 & $2.11 \mathrm{E}-05$ \\
$\mathrm{M}_{\mathrm{W}}$ TSP-d4 (g/mol) & 172.266129 & 0.002831 & $1.64 \mathrm{E}-05$ \\
$\mathrm{~m}$ Sample (mg) & 399.987211 & 0.001155 & $2.89 \mathrm{E}-06$ \\
$\mathrm{~m}$ Reference (mg) & 7.309667 & 0.002309 & 0.000316 \\
& & & 0.002633 \\
\hline Ethanol Concentration in water \% & 0.08123 & & \\
Combined uncertainty, u & 0.00021 & & \\
Expanded uncertainty, U (k=2) & 0.00043 & & \\
\hline
\end{tabular}




\subsection{Application of two different concentrations for ethanol in water sample by qNMR}

Ethanol concentration was determined at two different levels in water by qNMR. Five different sub-samples were prepared per day for each solution and analyzed on three different days. A total of fifteen NMR sub-samples were prepared from each concentration. The results for each day are given in Table 2 for low and high concentrations.

Table 3. qNMR results for two different concentrations of ethanol samples

\begin{tabular}{lcccccc}
\hline \multirow{2}{*}{$\begin{array}{c}\text { Ethanol in } \\
\text { Water }\end{array}$} & \multicolumn{2}{c}{ Low Level Concentration $(\mathbf{m g} / \mathbf{g})$} & \multicolumn{3}{c}{ High Level Concentration $(\mathbf{m g} / \mathbf{g})$} \\
Day 1 & Day 2 & Day 3 & Day 1 & Day 2 & Day 3 \\
\hline Sample 1 & 0.8053 & 0.8180 & 0.8256 & 3.8038 & 3.7973 & 3.8134 \\
Sample 2 & 0.8116 & 0.8088 & 0.8128 & 3.8155 & 3.7993 & 3.8009 \\
Sample 3 & 0.8114 & 0.7999 & 0.8231 & 3.8261 & 3.8050 & 3.7978 \\
Sample 4 & 0.8149 & 0.8071 & 0.8050 & 3.7936 & 3.8069 & 3.7997 \\
Sample 5 & 0.8068 & 0.8230 & 0.8117 & 3.7926 & 3.7912 & 3.8005 \\
\hline Mean & 0.8100 & 0.8113 & 0.8156 & 3.8063 & 3.7999 & 3.8025 \\
SD & 0.0039 & 0.0092 & 0.0085 & 0.0144 & 0.0063 & 0.0062 \\
\hline Com. Unc. u & 0.0020 & 0.0042 & 0.0039 & 0.0078 & 0.0052 & 0.0052 \\
Exp. Unc. U & 0.0040 & 0.0084 & 0.0079 & 0.0156 & 0.0105 & 0.0104 \\
\hline
\end{tabular}

Averages and uncertainty values of 15 sub-samples for each concentration were found as follows. The value for low concentration was found to be $0.8123 \mathrm{mg} / \mathrm{g}$ and the expanded uncertainty was 0.0043 $\mathrm{mg} / \mathrm{g}$. The value for high concentration was found to be $3.8029 \mathrm{mg} / \mathrm{g}$ and the expanded uncertainty was $0.0101 \mathrm{mg} / \mathrm{g}$.

\section{Conclusion}

The qNMR provides significant advantages over other chromatographic, spectroscopic and titrimetric methods, considering lesser analysis time, faster method development, easier data analysis and readiness of the instrument all the time. In this study, two different ethanol solutions, having lower and higher concentrations were studied. At both concentrations, the amount of ethanol was determined and reported with all the uncertainty components. It has been shown that the NMR instrument can be used as an important analytical technique for quantitative calculations of low concentrations of alcohol or metabolites in liquid solutions with high reproducibility and low uncertainty.

\section{Acknowledgements}

The authors would like to thank Professor Turan Ozturk, Istanbul Technical University for excellent technical support.

\section{References}

[1] U. Holzgrabe, (2008), Chapter 5 - qNMR Spectroscopy in Drug Analysis - A General View, NMR Spectroscopy in Pharmaceutical Analysis, 131-137, Amsterdam.

[2] M. Weber, C. Hellriegel, A. Rück, R. Sauermoser and J. Wüthrich, (2013). Using high-performance quantitative NMR (HP-qNMR ${ }^{\circledR}$ ) for certifying traceable and highly accurate purity values of organic reference materials with uncertainties $<0.1 \%$, Accredit Qual. Assur. 18:(2), 91-98.

[3] T. Ohtsuki, K. Sato, N. Sugimoto, H. Akiyama and Y. Kawamura, (2012). Absolute quantitative analysis for sorbic acid in processed foods using proton nuclear magnetic resonance spectroscopy, Anal. Chim. Acta. 734, 54-61. 
[4] T. Ohtsuki, K. Sato, N. Sugimoto, H. Akiyama and Y. Kawamura, (2012). Absolute quantification for benzoic acid in processed foods using quantitative proton nuclear magnetic resonance spectroscopy, Talanta. 99, 342-348.

[5] M.W. Couch, N.P. Das, K.N. Scott, C.M. Williams and R.L. Foltz, (1973). Identification and quantitative determination of saccharin in biological fluids, Biochem. Med. Metab. B. 8:(3), 362-370.

[6] J.C. Lindon, J.K. Nicholson, E. Holmes and J.R. Everett, (2000). Metabonomics: Metabolic processes studied by NMR spectroscopy of biofluids, Concept Magnetic Res. 12:(5), 289-320.

[7] B. Cartigny, N. Azaroual, M. Imbenotte, D. Mathieu, G. Vermeersch, J.P. Goulle and M. Lhermitte, (2004). Determination of glyphosate in biological fluids by ${ }^{1} \mathrm{H}$ and ${ }^{31} \mathrm{P}$ NMR spectroscopy, Forensic Sci. Int. 143:(2-3), 141-5.

[8] E.J. Saude, C.M. Slupsky and B.D. Sykes, (2006). Optimization of NMR analysis of biological fluids for quantitative accuracy, Metabolomics. 2:(3), 113-123.

[9] T.N. Kolokolova, O.Y. Savel'ev and N.M. Sergeev, (2011). Metabolic analysis of human biological fluids by 1H NMR spectroscopy, J. Anal. Chem. 63:(2), 104-120.

[10] R.K. Rai and N. Sinha, (2012). Fast and accurate quantitative metabolic profiling of body fluids by nonlinear sampling of ${ }^{1} \mathrm{H}_{-}{ }^{13} \mathrm{C}$ two-dimensional nuclear magnetic resonance spectroscopy, Anal. Chem. 84:(22), 10005-11.

[11] T.J. Athersuch, S. Malik, A. Weljie, J. Newton and H.C. Keun, (2013). Evaluation of 1H NMR metabolic profiling using biofluid mixture design, Anal. Chem. 85:(14), 6674-81.

[12] İ. Ün, B. Vatansever, A. Şimşek and A.C. Gören, (2016). Comparison of qNMR and HPLC-UV techniques for measurement of coenzyme $\mathrm{Q}_{10}$ in dietary supplement capsules, J. Chem. Metrol. 10:(1), 110 .

[13] S. Gunduz, H. Yilmaz and A.C. Goren, (2013). Halal food and metrology: ethyl alcohol contents of beverages, J. Chem. Metrol. 7:(1), 7-9.

[14] E. López-Rituerto, S. Cabredo, M. López, A. Avenoza, J.H. Busto and J.M. Peregrina, (2009). A Thorough Study on the Use of Quantitative ${ }^{1} \mathrm{H}$ NMR in Rioja Red Wine Fermentation Processes, J. Agr. Food Chem. 57:(6), 2112-2118.

[15] W. da Silva Nunes, C.S. de Oliveira and G.B. Alcantara, (2016). Ethanol determination in frozen fruit pulps: an application of quantitative nuclear magnetic resonance, Magn. Reson. Chem.: MRC. 54:(4), $334-40$.

[16] International conference on harmonization ( $\mathrm{ICH})$ of technical requirement for registration of Pharmaceutical for human use, topic Q3C, Impurities guideline for residual solvents, (2005), www.ich.org.

[17] G.R. Fulmer, A.J.M. Miller, N.H. Sherden, H.E. Gottlieb, A. Nudelman, B.M. Stoltz, J.E. Bercaw and K.I. Goldberg, (2010). NMR Chemical Shifts of Trace Impurities: Common Laboratory Solvents, Organics, and Gases in Deuterated Solvents Relevant to the Organometallic Chemist, Organometallics. 29:(9), 2176-2179.

[18] F. Malz and H. Jancke, (2005). Validation of quantitative NMR, J. Pharma. Biomed. Anal. 38:(5), 81323.

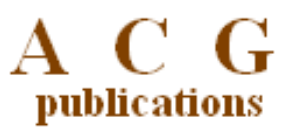

(C) 2017 ACG Publications 